\title{
Alpha-Linked Galactooligosaccharide Suppresses Small Intestinal Eosinophil Infiltration and Improves Growth Performance in Weaning Pigs
}

\author{
Takamitsu TSUKAHARA ${ }^{1,2)}$, Ryo INOUE ${ }^{1,2)}$, Nobuyuki SHIMOJO'), Keizo NAKAYAMA ${ }^{2)}$, Sanshiro SAITO ${ }^{3)}$, \\ Toshiro SATO ${ }^{3)}$, Tetsuya ITOH $^{4)}$, Koki FUJITA ${ }^{4)}$ and Kazunari USHIDA ${ }^{1) *}$ \\ ${ }^{1)}$ Laboratory of Animal Science, Kyoto Prefectural University, Shimogamo, Kyoto 606-8522, ${ }^{2}$ Kyoto Institute of Nutrition \& Pathology, \\ Uji-tawara, Kyoto 610-0231, 3) J-OIL Mills, Fine Chemical \& Foods Laboratories, Nakashinden, Fukuroi, Shizuoka 437-1111 and \\ ${ }^{4)}$ Ensuiko Sugar Refining, Carbohydrate Research Laboratory, Fukuura, Yokohama 236-0004, Japan
}

(Received 18 October 2009/Accepted 13 December 2009/Published online in J-STAGE 25 December 2009)

\begin{abstract}
A healthy pig shows significant eosinophil infiltration in the lamina propria of the small intestine. Although the exact role of these infiltrated eosinophils in healthy pigs is unclear, eosinophil infiltration is a well-known phenomenon that is frequently observed during an allergic status. Alpha-linked galactooligosaccharide (GOS) reduces eosinophil infiltration into broncho-alveolar lavage fluid of an allergic airway eosinophilia model. We evaluated the effect of GOS oral administration on the suppression of eosinophil infiltration in the small intestine of healthy weaned pigs. Nine 21-day-old pigs were purchased and divided into three groups. One group was fed the basal diet supplemented with sucrose at $0.11 \%(\mathrm{C})$, one group was fed the basal diet supplemented with GOS at $1.17 \%$ (GOS A) and one group was fed the basal diet supplemented with GOS at $0.03 \%$ (GOS B). Each group was fed its respective diet throughout this study (10 days). The daily body weight gain from $\mathrm{d} 3$ to $\mathrm{d} 10$ was significantly bigger in the GOS B group than in the other groups. The feed conversion ratios from d0 to d10 were two times lower in the GOS B group than in the C group. Dietary GOS suppressed eosinophil infiltration in the small intestine. However, GOS administration had no effect on the organic acid level or microbial composition in the small and large intestinal digesta.

KEY WORDS: alpha-linked galactooligosaccharide, eosinophil infiltration, growth performance, weaning pig.
\end{abstract}

J. Vet. Med. Sci. 72(5): 547-553, 2010

A healthy pig shows significant eosinophil infiltration in the lamina propria of the small intestine despite the absence of parasite infection [15]. In a previous study, it was also reported that eosinophils are observed predominantly in the small intestines of germ-free pigs [9]. Although the exact role of these infiltrated eosinophils in healthy pigs is unclear, eosinophil infiltration is a well-known phenomenon that is frequently observed during an allergic status, such as asthma [18], food allergy [3] and ulcerative colitis [6]. Furthermore, it has been demonstrated that a large number of eosinophils infiltrate not only the intestine but also the bone marrow, spleen, lymph node, thymus, tonsils, eyelids, snout, skin, cerebral meninges and lung when a pig contracts an edema disease (ED) [8]. Therefore, the pathogenesis of ED involves allergic symptoms that may induce significant retardation of pig growth.

Alpha-linked galactooligosaccharide (GOS) is synthesized enzymatically from galactose by $\alpha$-galactosidase and is currently regarded as a prebiotic [19]. It has been demonstrated that GOS is not hydrolyzed by human salivary amylase, porcine pancreatic amylase or glycosidases in the rat intestinal brush border membrane and that GOS is utilized by Bifidobacterium bifidum and Clostridium butyricum [19]. Furthermore, GOS seems to possess an immunomodulatory function, according to Sonoyama et al., who reported that administration of GOS to ovalbumin-sensi-

\footnotetext{
* Correspondence to: Prof. Ushida, K., Laboratory of Animal Science, Kyoto Prefectural University, Shimogamo, Kyoto 6068522, Japan.

e-mail: k_ushida@kpu.ac.jp
}

tized Brown Norway rats (a model of allergic airway eosinophilia) significantly reduced eosinophil infiltration into broncho-alveolar lavage fluid [12].

In this study, we evaluated the effect of GOS oral administration on the suppression of eosinophil infiltration in the small intestines of healthy weaned pigs. Although the effect of GOS on eosinophil infiltration into broncho-alveolar lavage fluid is unlikely to be the result of modification of the bronchious luminal microbiota [12], this may not be the case when eosinophils infiltrate the tissue of the small intestine, where luminal microbiota may be more dense and have a more intensive effect than on the bronchium. Therefore, we further evaluated the luminal microbiota and immunologic responses in the intestine when pigs were fed food containing GOS.

\section{MATERIALS AND METHODS}

Animals, materials and basal diet: Nine (six female and three male) 21-day-old crossbred (Landrace x Large white $\mathrm{x}$ Duroc) pigs weighing approximately $5 \mathrm{~kg}$ each were purchased from a commercial pig farm. The animals were healthy and did not receive any antimicrobials prior to the study. The pigs were housed in pens at Kyoto Prefectural University, Kyoto, Japan. They were divided into three groups containing one male and two females to obtain a similar mean body weight, and each group was housed in a pen. The temperature was maintained with brooders at $30^{\circ} \mathrm{C}$ (determined on the floor just under the brooder).

The animals were fed a commercial diet for weaning pigs 
(SDS No.1; Nippon Formula Feed, Yokohama, Japan). This basal diet was free from intestinal microbiota modifiers, such as antimicrobials and probiotics. The nutrient composition of this diet was the same as that described previously [13]. The diet and water were given ad libitum throughout the study. The experimental animals were handled in accordance with the guidelines for animal studies of the Experimental Animal Committee of Kyoto Prefectural University.

Three experimental groups were created as follows: one group was fed the basal diet supplemented with control sugar at $0.25 \%$ (C group), one group was fed the basal diet supplemented with GOS A at $2.6 \%(\mathrm{w} / \mathrm{w})$ (GOS A group) and one group was fed the basal diet supplemented with GOS B at $0.25 \%(w / w)$ (GOS B group). The control sugar contained sucrose $(45 \%)$ and silicic acid $(40 \%)$ with moisture $(15 \%)$. GOS A contained GOS [45.0\%; $\alpha$-galactosyl disaccharide (26.0\%), $\alpha$-galactosyl trisaccharide (12.9\%) and $\alpha$-garactosyl tetra- or longer chain-saccharide (6.1\%)] and silicic acid (40.0\%) with moisture (15.0\%). GOS B contained GOS $[11.0 \%$; $\alpha$-galactosyl disaccharide $(4.9 \%)$, $\alpha$-galactosyl glucose (6.1\%)], monosaccharides such as galactose $(34.0 \%)$ and silicic acid $(40.0 \%)$ with moisture $(15.0 \%)$.

Experimental design: Each group was fed its respective diet throughout this study (10 days). Clinical signs of diarrheal feces were checked daily using the following score $(0$, normal feces; 1 , loose stool; 2 , moderate diarrhea; 3 , severe diarrhea) as described previously [14]. Body weight was measured on $\mathrm{d} 0, \mathrm{~d} 3$ and $\mathrm{d} 10$. The remaining feed was weighed on $\mathrm{d} 3$ and $\mathrm{d} 10$. On $\mathrm{d} 10$, all pigs were euthanized by exsanguination under general anesthesia with intraperitoneal injections of sodium pentobarbital (Somnopentyl, Kyoritsu, Tokyo, Japan). After a midline incision, blood was collected from the abdominal aorta. The entire intestine was removed and separated into the small intestine and cecum after string ligation. The small intestine was evenly divided into four segments. The proximal to distal segments were numbered in order from S1 ro S4. These segments of the small intestine and cecum were longitudinally incised, and a distal portion of each segment was fixed in a $10 \%(\mathrm{v} /$ v) phosphate-buffered formalin solution. The remaining distal portion was used for an immunological evaluation. The mucosa of a portion of the intestine was removed with a clean slide glass and was then immersed in RNAlater (Ambion, Tokyo, Japan) overnight at $4^{\circ} \mathrm{C}$. The samples were then stored at $-80^{\circ} \mathrm{C}$ until subsequent RNA extractions. The luminal content of the small intestine (S3 and S4 pooled sample) and cecum was also collected and stored at $-80^{\circ} \mathrm{C}$ until analysis.

Analyses of luminal contents: The luminal contents were used for immunoglobulin A (IgA) quantitation, measurement of organic acid concentration and molecular ecological analysis of the luminal microbiota. The IgA concentration was determined using a commercial ELISA kit (porcine IgA ELISA Quantitation kit; Bethyl, Montgomery, TX, U.S.A.) as described previously [17].

Organic acid [short-chain fatty acid (SCFA), succinate, lactate and formate] in small intestinal and cecal digesta was analyzed by ion-exclusion HPLC as described elsewhere [16].

The composition of the small intestinal and cecal microbiota was examined using Temperature Gradient Gel Electrophoresis (TGGE) analysis as described previously [15], with slight modifications. Briefly, bacterial genomic DNA was extracted from the digesta using the method of Godon et al. [2]. PCR amplification and electrophoreses were performed as described in Inoue et al. [4].

Blood cell count analysis: The eosinophils in the heparinized blood from the abdominal vein were counted by Japan Clinical Laboratories (Kyoto, Japan).

Histological studies: The histological studies were similar to those described elsewhere [15]. Briefly, the formalinfixed intestinal tissues were further cut into cross sections with approximate lengths of $10 \mathrm{~mm}$. Each intestinal segment was embedded in paraffin wax. Microsections that were $3-\mu \mathrm{m}$ thick were prepared and stained with hematoxylin and eosin (HE) or Luna for light microscopic examination. The eosinophils were counted for the whole area of the mucosal tissue of S2 and S3 at 200× magnification in the Luna stain.

Immunologic analysis: Total RNA was extracted from the samples using NucleoSpin ${ }^{\circledR}$ RNA II (MACHEREYNAGEL, Duren, Germany). On-column DNase treatment was performed using the RNase-Free DNase I included in the kit. The concentration of the extracted total RNA was measured with a NanoDrop ND1000 spectrophotometer (NanoDrop Technologies, Wilmington, DE, U.S.A.), and $150 \mathrm{ng}$ of the total RNA was used for reverse transcription using a ReverTraAce- $\alpha$ (TOYOBO, Osaka, Japan) with an Oligo (dT)20 primer. All procedures were performed according to the manufacturer's instructions.

Real-time PCR was performed using a Rotor-Gene 6200 (Qiagen, Tokyo, Japan). The expression of 11 genes (Table 1), including a housekeeping gene, glyceraldehyde-3-phosphate dehydrogenase (GAPDH), was evaluated. Amplification was carried out in a $10-\mu \mathrm{L}$ reaction volume containing $5 \mu \mathrm{L}$ of SYBR premix EX taq ${ }^{\mathrm{TM}}$ (Perfect Real Time; Takara Bio, Shiga, Japan), $0.6 \mu \mathrm{L}$ cDNA and $0.4 \mu \mathrm{M}$ of each primer. The thermal cycling profile was $5 \mathrm{~min}$ at $95^{\circ} \mathrm{C}$ followed by 40 cycles of $15 \mathrm{sec}$ at $95^{\circ} \mathrm{C}, 5 \mathrm{sec}$ at the appropriate annealing temperature (Table 1), and $15 \mathrm{sec}$ at $72^{\circ} \mathrm{C}$. Melting curves were generated for each sample to verify the specificity of the amplicons. To prepare a standard curve, plasmids containing the PCR product of each gene in the pGEM-T Easy vector (Promega, Tokyo, Japan) were generated and included in every run. The transcript copy number for each sample was calculated from the standard curve and normalized to the copy number for GAPDH.

Statistical analyses: Values are given as the means with standard error $(\mathrm{n}=3)$. Either a complete randomized design 1-way ANOVA or the Kruskal-Wallis test, depending on the results of the Bartlett test, was used to analyze the differences in body weight gain, eosinophil numbers in the blood and mucosa, gene expression in the mucosa, and organic 
Table 1. Primers used in this study

\begin{tabular}{|c|c|c|c|}
\hline & Sequences $\left(5^{\prime}-3^{\prime}\right)$ & Product size & Annealing temperature $\left({ }^{\circ} \mathrm{C}\right)$ \\
\hline \multirow[t]{2}{*}{ IL-4 } & F GCC GGG CCT CGA CTG T & $105 \mathrm{bp}$ & 60 \\
\hline & R TCC GCT CAG GAG GCT CTT C & & \\
\hline \multirow[t]{2}{*}{ IL-5 } & F GAC TGG TGG CAG AGA CCT TGA C & $120 \mathrm{bp}$ & 60 \\
\hline & R CTT CAA TGC ATA GTT GGT GAT TTG T & & \\
\hline \multirow[t]{2}{*}{ IL-6 } & F ATG GCA GAA AAA GAC GGA TG & $216 \mathrm{bp}$ & 60 \\
\hline & R GTG GTG GCT TTG TCT GGA TT & & \\
\hline \multirow[t]{2}{*}{ IL-8 } & F TAG GAC CAG AGC CAG GAA GA & $230 \mathrm{bp}$ & 62 \\
\hline & R CAG TGG GGT CCA CTC TCA AT & & \\
\hline \multirow[t]{2}{*}{ IL-10 } & F GGG CTA TTT GTC CTG ACT GC & $110 \mathrm{bp}$ & 62 \\
\hline & R CAA AGG GGC TCC CTA GTT TC & & \\
\hline \multirow[t]{2}{*}{ IFN- $\gamma$} & F AGC ATG GAT GTG ATC AAG CA & $248 \mathrm{bp}$ & 60 \\
\hline & $\mathrm{R}$ TGC AGG CAG GAT GAC AAT TA & & \\
\hline \multirow[t]{2}{*}{ TNF- $\alpha$} & F CCC CTG TCC ATC CCT TTA TT & $200 \mathrm{bp}$ & 60 \\
\hline & R AAG CCC CAG TTC CAA TTC TT & & \\
\hline \multirow[t]{2}{*}{ CCL28 } & F ACT TGG CTG CTG TCA TCC TT & $181 \mathrm{bp}$ & 60 \\
\hline & $\mathrm{R}$ TCA TGC TTC TCC TGA TGT GC & & \\
\hline \multirow[t]{2}{*}{ RANTES } & F AGA AAT GGG TGC GGG AGT A & $200 \mathrm{bp}$ & 60 \\
\hline & R GCT GGG ACA AGA GCA AGA A & & \\
\hline \multirow[t]{2}{*}{ pIgR } & F CCT GCA ATG TGG TCA TCA AC & $238 \mathrm{bp}$ & 60 \\
\hline & R GAG GAT CTT GGG GGA ATC AT & & \\
\hline \multirow[t]{2}{*}{ GAPDH } & F AGC AAT GCC TCC TGC ACC AC & $189 \mathrm{bp}$ & 60 \\
\hline & R AAG CAG GGA TGA TGT TCT GG & & \\
\hline
\end{tabular}

acid and IgA concentrations of the digesta. TukeyKramer's post-hoc comparison (parametric or non-parametric) was used for multiple comparisons when needed. The Kruskal-Wallis test was used to analyze differences in the fecal and pathologic scores. Non-parametric TukeyKramer's post-hoc comparison was used for multiple comparisons when needed. A difference among means was considered significant at $\mathrm{p}<0.05$ or showed a tendency to be significant at $\mathrm{p}<0.1$ levels in all statistical analyses. All data were analyzed by StatLight 2000 (Yukms Co., Ltd., Tokyo, Japan) or Statcel [20].

\section{RESULTS}

Fecal scores: The total score (from d0 to d10) of feces was 4.0 in the $\mathrm{C}$ group, 3.3 in the GOS A group and 1.3 in the GOS B group. The score was 2 times lower in the GOS $\mathrm{B}$ group than in the $\mathrm{C}$ group; however, no statistical significance was observed among the groups.

Body weight gain, feed intake and feed conversion ratio (Table 2): The daily body weight gain from $\mathrm{d} 3$ to $\mathrm{d} 10$ was significantly higher in the GOS B group than in the other groups $(\mathrm{p}<0.05)$. On the other hand, the body weight gain from $\mathrm{d} 0$ to $\mathrm{d} 3$ in the GOS B group was the lowest. Therefore, no significant difference was observed among the experimental groups from $\mathrm{d} 0$ to $\mathrm{d} 10$. Feed intake from $\mathrm{d} 0$ to d3 was two times lower in the GOS B group, 1.5 times higher in the GOS A group than in the $\mathrm{C}$ group. However, feed intake from $\mathrm{d} 3$ to $\mathrm{d} 10$ in the GOS B group was 1.5 times higher than in the $\mathrm{C}$ group. Therefore, feed intake from $\mathrm{d} 0$ to $\mathrm{d} 10$ was 1.4 times higher in the GOS fed groups than in the $\mathrm{C}$ group. The feed conversion ratios from $\mathrm{d} 0$ to $\mathrm{d} 10$ were two times lower in the GOS B group than in the $\mathrm{C}$ group.

Eosinophils in the blood: The mean numbers of eosinophils in the abdominal blood were 190 cells $/ \mu \mathrm{L}$ in the $\mathrm{C}$ group, 270 cells $/ \mu \mathrm{L}$ in the GOS A group and 213 cells $/ \mu \mathrm{L}$ in the GOS B group. There was no statistical significance.

Organic acid and IgA concentration in digesta (Table 3): The organic acid (lactate, acetate, propionate, n-butyrate and n-valerate) concentration was not significantly affected by dietary GOS administration at any portion of the intes-

Table 2. Effect of dietary GOS administration on body weight gain, feed intake and feed conversion ratio in weaning piglets ${ }^{\mathrm{a})}$

\begin{tabular}{|c|c|c|c|c|c|c|c|c|c|}
\hline \multirow[b]{2}{*}{ Group } & \multicolumn{3}{|c|}{ Body weight gain $(\mathrm{g} / \mathrm{d})^{\mathrm{b})}$} & \multicolumn{3}{|c|}{ Feed intake $(\mathrm{g} / \mathrm{d})$} & \multicolumn{3}{|c|}{ Feed conversion ratio } \\
\hline & $\mathrm{d} 0-\mathrm{d} 3$ & $\mathrm{~d} 3-\mathrm{d} 10$ & $\mathrm{~d} 0-\mathrm{d} 10$ & $0-3 d$ & $3-10 \mathrm{~d}$ & $0-10 \mathrm{~d}$ & $0-3 d$ & $3-10 d$ & $0-10 \mathrm{~d}$ \\
\hline $\mathrm{C}$ & $11.1 \pm 29.4^{\mathrm{ab}}$ & $57.1 \pm 16.5^{\mathrm{B}}$ & $43.3 \pm 8.8$ & 44.4 & 123.8 & 100.0 & 4.00 & 2.17 & 2.31 \\
\hline GOS A & $88.9 \pm 48.4^{\mathrm{a}}$ & $66.7 \pm 25.2^{\mathrm{B}}$ & $73.3 \pm 31.8$ & 66.7 & 171.4 & 140.0 & 0.75 & 2.57 & 1.91 \\
\hline GOS B & $-77.8 \pm 29.4^{\mathrm{b}}$ & $190.5 \pm 25.2^{\mathrm{A}}$ & $110.0 \pm 10.0$ & 22.2 & 190.5 & 140.0 & - & 1.00 & 1.27 \\
\hline
\end{tabular}

a) Values are means $\pm \mathrm{SE}(\mathrm{n}=3)$. Parametric Tukey-Kramer post-hoc comparison was used for multiple comparisons when significant differences were found using a completely randomized design one-way ANOVA.

b) Means in a column without common capital $(\mathrm{p}<0.05)$ or small $(\mathrm{p}<0.1)$ letters differ significantly or tend to differ, respectively. 
Table 3. Effect of dietary GOS administration on organic acid and immunoglobulin concentrations in the luminal contents ${ }^{\mathrm{a})}$

\begin{tabular}{|c|c|c|c|c|c|c|c|c|c|c|}
\hline \multirow[b]{3}{*}{ Group } & \multicolumn{7}{|c|}{ Organic acid concentration ( $\mathrm{mmol} / \mathrm{kg}$ digesta $)^{\mathrm{b})}$} & & \multicolumn{2}{|c|}{ IgA concentration ( $\mathrm{mg} / \mathrm{kg}$ digesta) } \\
\hline & \multicolumn{3}{|c|}{ Small intestine } & \multicolumn{4}{|c|}{ Cecum } & \multirow[b]{2}{*}{ n-valerate } & \multirow{2}{*}{$\begin{array}{l}\text { Small } \\
\text { intestine }\end{array}$} & \multirow[t]{2}{*}{ Cecum } \\
\hline & Lactate & Acetate & Propionate & Lactate & Acetate & Propionate & n-butyrate & & & \\
\hline $\mathrm{C}$ & $5.3 \pm 1.4$ & $1.0 \pm 0.3$ & $1.0 \pm 0.2$ & $6.8 \pm 2.5$ & $49.1 \pm 11.0$ & $26.5 \pm 6.1$ & $8.8 \pm 1.3$ & $1.4 \pm 0.4$ & $100.0 \pm 26.2$ & $17.6 \pm 5.7$ \\
\hline GOS A & $5.1 \pm 1.4$ & $0.9 \pm 0.2$ & $0.2 \pm 0.2$ & $5.2 \pm 5.2$ & $41.9 \pm 7.6$ & $18.6 \pm 1.6$ & $7.7 \pm 1.7$ & $1.7 \pm 0.9$ & $129.4 \pm 24.8$ & $12.7 \pm 7.9$ \\
\hline GOS B & $6.7 \pm 0.7$ & $1.5 \pm 0.3$ & $0.9 \pm 0.2$ & $4.8 \pm 2.5$ & $60.2 \pm 14.1$ & $23.9 \pm 9.2$ & $9.8 \pm 5.9$ & $2.0 \pm 0.9$ & $73.3 \pm 5.2$ & $13.8 \pm 10.3$ \\
\hline
\end{tabular}

a) Values are means \pm SE $(n=3)$. A completely randomized design 1-way ANOVA was used to analyze the differences for each portion. However, no significant difference was observed.

b) Examination of the luminal contents revealed only trace amounts of succinate, formate, iso-butyrate and iso-valerate in the small intestine and cecum, and n-butyrate and n-valerate in the small intestine; therefore, they were omitted from consideration.

\begin{tabular}{ccccc} 
Table 4. & Effect of dietary GOS administration on pathological scores in the intestine \\
\hline Intestine & Group & $\begin{array}{c}\text { Edematous } \\
\text { lamina propria }\end{array}$ & $\begin{array}{c}\text { Swollen } \\
\text { lymphoid follicles }\end{array}$ & $\begin{array}{c}\text { Eosinophil } \\
\text { infiltration }\end{array}$ \\
\hline S1 & C & $1.7 \pm 0.3$ & $0.3 \pm 0.3$ & $1.0 \pm 0.0$ \\
& GOS A & $2.0 \pm 0.0$ & $0.0 \pm 0.0$ & $1.0 \pm 0.0$ \\
S2 & GOS B & $1.7 \pm 0.3$ & $0.0 \pm 0.0$ & $1.0 \pm 0.0$ \\
& C & $1.3 \pm 0.3$ & $0.7 \pm 0.3$ & $1.0 \pm 0.0$ \\
S3 & GOS A & $1.3 \pm 0.3$ & $0.0 \pm 0.0$ & $1.3 \pm 0.3$ \\
& GOS B & $1.7 \pm 0.3$ & $0.0 \pm 0.0$ & $1.3 \pm 0.3$ \\
& C & $1.0 \pm 0.0$ & $0.0 \pm 0.0$ & $2.0 \pm 0.0$ \\
S4 & GOS A & $0.7 \pm 0.3$ & $0.0 \pm 0.0$ & $1.7 \pm 0.3$ \\
& GOS B & $1.7 \pm 0.3$ & $0.7 \pm 0.3$ & $1.7 \pm 0.3$ \\
Cecum & GOS A & $1.0 \pm 0.6$ & $2.0 \pm 0.0$ & $2.0 \pm 0.0$ \\
& GOS B & $1.3 \pm 0.3$ & $2.0 \pm 0.0$ & $1.7 \pm 0.3$ \\
& C & $1.7 \pm 0.3$ & $2.0 \pm 0.0$ & $2.0 \pm 0.0$ \\
& GOS A & $1.3 \pm 0.9$ & $0.0 \pm 0.0$ & $0.0 \pm 0.0$ \\
& GOS B & $1.0 \pm 0.0$ & $0.0 \pm 0.0$ & $0.0 \pm 0.0$ \\
& & $1.7 \pm 0.7$ & $0.3 \pm 0.3$ & $0.0 \pm 0.0$
\end{tabular}

a) Pathological scores: 0 for normal, 1 for slightly abnormal, 2 for moderately abnormal, 3 for severely abnormal, as described previously [15]. Values are means $\pm \mathrm{SE}(\mathrm{n}=3)$. The Kruskal-Wallis test was used to analyze the differences in each score.

tine. Other organic acids, such as succinate, formate, isobutyrate and iso-valerate, were detected in amounts of less than $2 \mathrm{mmol} / \mathrm{kg}$ digesta; therefore, we omitted them from consideration. No n-butyrate or n-valerate was detected in the small intestine.

The IgA concentration was not significantly affected by dietary GOS administration in any portion of the intestine.

Dendrogram from TGGE analysis: The diversity of the luminal microbiota in the small intestine and cecum was evaluated with a dendrogram generated from the PCRTGGE band profiles. The profiles of the small intestinal and cecal microbiota were less clearly separated depending on GOS feeding; for example, the profiles between the $\mathrm{C}$ and GOS A groups were combined (data not shown).

Histological evaluations (Table 4, Fig. 1): An edematous lamina propria was observed in the small and large intestines of all pigs. However, the level of edema was not different among the experimental groups in any portion of the intestine. The lymphoid follicles were particularly swollen in the distal portion of the small intestine (S4). However, the scores for swollen lymphoid follicles were not significantly affected by GOS administration in any portion of the intestine. Eosinophil infiltration in the lamina propria was observed in the small intestines of all pigs. However, the levels of infiltration were not different for the experimental groups in any portion of the small intestine. No sign of histological abnormalities, such as erosion, ulcer, atrophy, hypertrophy and villous loss in the mucosa or leukocyte infiltration, was observed except for eosinophil infiltration in the lamina propria of the small intestine. The same was true for the large intestine.

The score of eosinophil infiltration was not affected by GOS feeding. Since the difference in the score of eosinophil infiltration in S2 and S3 was nearly significant, we further evaluated the eosinophil numbers in the lamina propria of $\mathrm{S} 2$ and S3. The mean number of eosinophils in the lamina propria of S2 was not significantly different among the experimental groups. However, the number was 1.5 times lower in the GOS administration groups than in the $\mathrm{C}$ group. The mean number of eosinophils in the mucosa of S3 was significantly lower in the GOS administration groups than in the $\mathrm{C}$ group $(\mathrm{p}<0.05)$.

Gene expression in the small intestinal mucosa (Figs. 2, 3): The S2 and S3 segments were further evaluated for the gene expressions of cytokines and chemokines in the mucosa. In S2, the gene expressions of IL- 4 and IFN- $\gamma$ were 


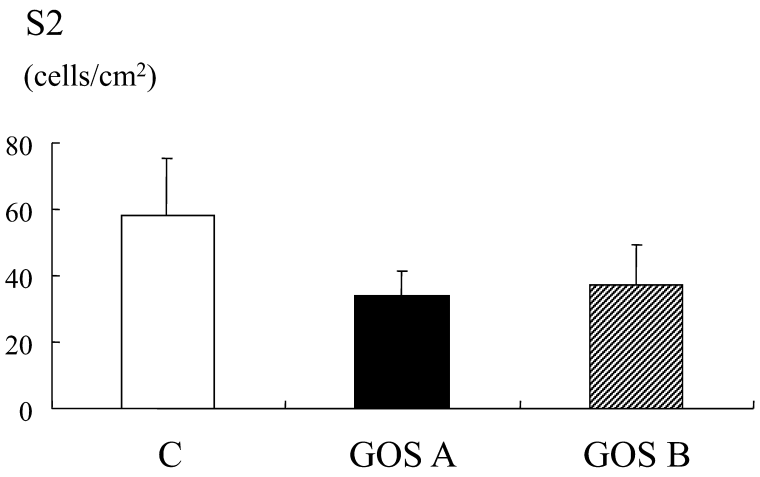

S3

$\left(\right.$ cells $\left./ \mathrm{cm}^{2}\right)$

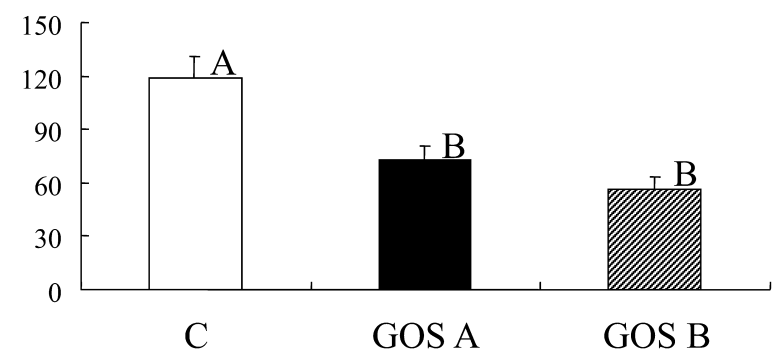

Fig. 1. Effect of dietary GOS administration on the numbers of eosinophil in the mucosa of S2 (A) and S3 (B) segments. Bars represent the means $(n=3)$, and error bars indicate the standard error. Open bars represent the $\mathrm{C}$ group, closed bars represent the GOS A group and slashed bars represent the GOS B group. Bars sharing the same letter are not significant different at $\mathrm{p}<0.05$.

up-regulated by GOS A administration $(\mathrm{p}<0.01)$. The gene expressions of IL-5, IL-6, IL-10, CCL28, RANTES and pIgR showed the same tendencies as those of IL-4 and IFN$\gamma$; however, there were no significant differences.

In the S3 segment, the gene expressions of IL-4 and IL-6 was up-regulated by GOS A administration $(p<0.1)$. The gene expressions of CCL28 and pIgR showed the same tendencies as those for IL-6; however, there were no significant differences.

\section{DISCUSSION}

The body weight gain was improved in the GOS B group from $\mathrm{d} 3$ to $\mathrm{d} 10$, but was not improved clearly in the GOS A group. On the other hand, the body weight was loosed in the GOS B from $\mathrm{d} 0$ to $\mathrm{d} 3$ (Table 2). The poor appetite observed in the GOS B group from $\mathrm{d} 0$ to $\mathrm{d} 3$ was probably the reason for this body weight loss. GOS B contained a small amount of monosaccharides, such as galactose $(0.09 \%$ in diet $)$, whereas GOS A contained no monosaccharides. However, it is unlikely that these monosaccharides affect body weight directly because such a low concentration of monosaccharides is unlikely to become an energy source that can affect body weight.
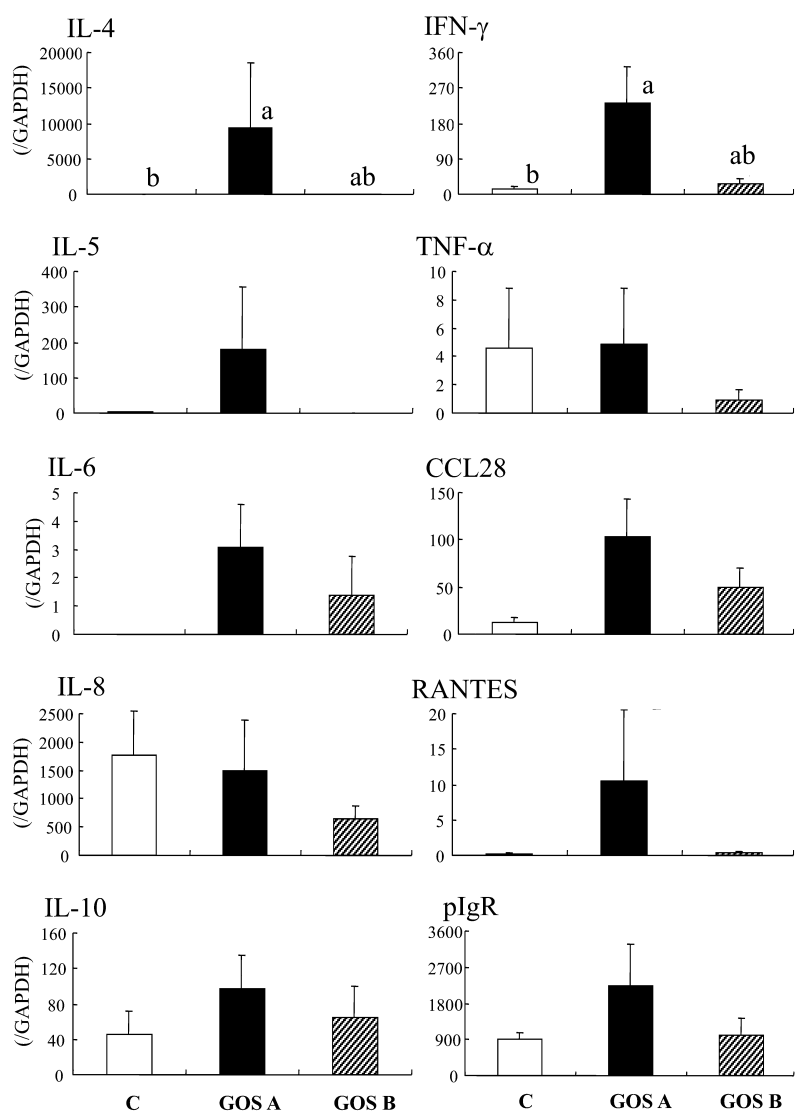

Fig. 2. Effect of dietary GOS administration on the gene expressions of cytokines and chemokines in the S2 mucosa. Bars represent the means $(n=3)$, and error bars indicate the standard error. Open bars represent the $\mathrm{C}$ group, closed bars represent the GOS A group and slashed bars represent the GOS B group. Bars sharing the same letter are not significant different at $\mathrm{p}<0.1$.

Administration of GOS to weaning piglets was successful in suppressing eosinophil infiltration in the small intestinal mucosa (Fig. 1). GOS A stimulated small intestinal gene expression of IL-4 (S2 and S3), IL-6 (S3) and IFN- $\gamma$ (S2), while GOS B did not stimulate cytokine gene expression in the small intestinal mucosa. Therefore, GOS A was more immunostimulant than GOS B. However, growth performance was more significantly improved by GOS B than by GOS A. An excess level of inflammatory cytokines reduces body weight gain in chickens [10]. It is still unclear whether the differing effects of GOS A and B on growth performance are caused either by the difference in the supplementation ratio of GOS $(1.17 \%$ and $0.03 \%$ for GOS A and B, respectively) or in the sugar composition. However, GOS B seems more appropriate as a growth promoter for healthy weaning pigs compared with GOS A.

The antigenic soybean product in feed induces frequent diarrhea; at the same time, it induces eosinophil infiltration and the loss of villi in the small intestines of piglets [1]. These symptoms consequently reduce the growth performance of weaning pigs [5]. GOS A administration may be 

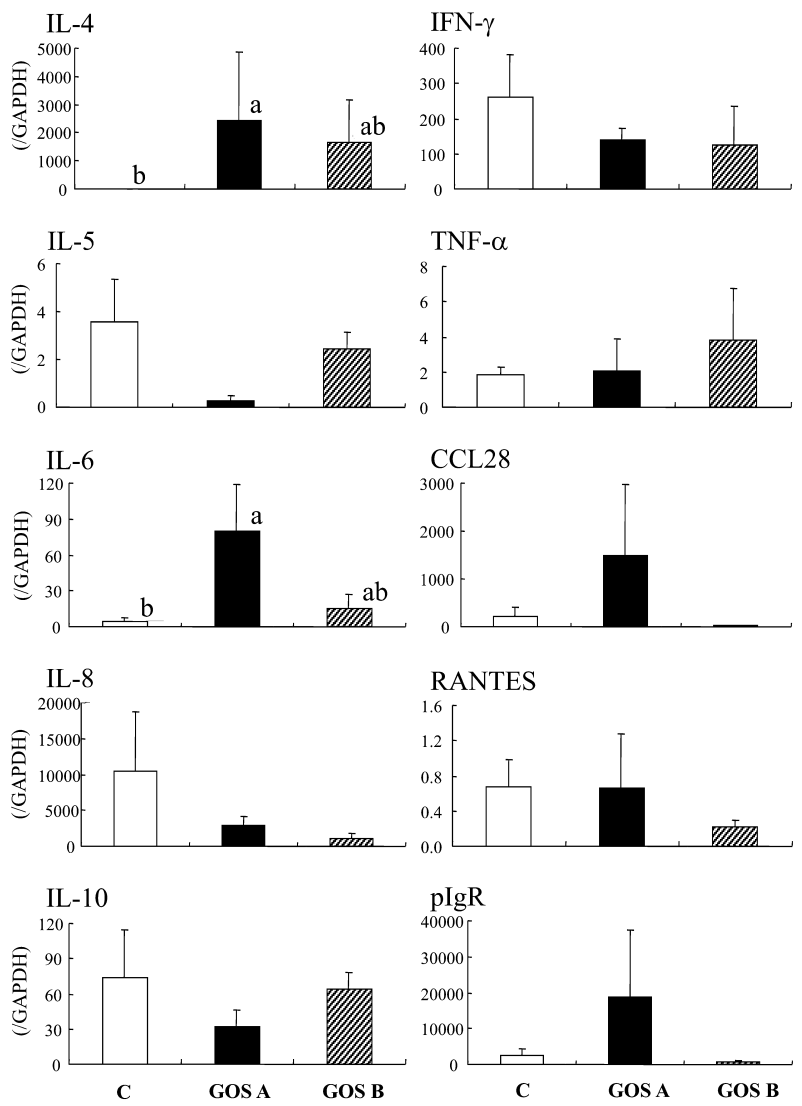

Fig. 3. Effect of dietary GOS administration on the gene expressions of cytokines and chemokines in the S3 mucosa. Bars represent the means $(n=3)$, and error bars indicate the standard error. Open bars represent the $\mathrm{C}$ group, closed bars represent the GOS A group and slashed bars represent the GOS B group. Bars sharing the same letter are not significant different at $\mathrm{p}<0.1$.

effective in improving these allergic symptoms in piglets affected by food allergies [1] or ED [8].

It is noteworthy that the stimulation of gene expression and prevention of eosinophil infiltration by GOS A administration was observed in a limited part of the small intestine (i.e., the IFN- $\gamma$ expression was up-regulated in S2 but not in S3). Another of our recent study also demonstrated the sitespecific immune response of Peyer's patch to oral administration of lactic acid bacteria [21]. The exact reason for these site-specific effects of orally administered materials is still unclear. This point needs to be elucidated further in the future.

GOS administration had no effect on the organic acid level in the digesta (Table 3) or the microbial composition. Therefore, in conclusion, the intestinal microbiota was not significantly affected by the administration of GOS. The results suggest that the suppression of eosinophil infiltration in the small intestine was independent of the prebiotic action of GOS, as shown by Sonoyama et al. [12] for eosinophil infiltration in the bronchium. Many reports have shown that dietary oligosaccharide modulates the immune function of the small intestine through a change in the large intestinal microbiota $[7,11]$. However, it is plausible that GOS directly affects the immune function of the small intestine. Indeed, expression of some cytokine genes in the small intestinal mucosa was stimulated by GOS A (Figs. 2 and 3). This finding further supports the direct immunomodulatory effect of GOS. However, most genes were significantly affected by administration of GOS A, especially IL-4, which is supposed to induce eosinophil infiltration, whereas the eosinophil infiltration in the small intestinal mucosa was suppressed (Fig. 1). One reason for this discrepancy was the lack of the cDNA sequence of porcine eotaxin, a critical chemokine for eosinophil infiltration; thus, its expression was not evaluated in this study. Further study, including identification of the cDNA sequence of eotaxin, will certainly be necessary to investigate this discrepancy. On the other hand, the gene expressions of pIgR and CCL28 were not significantly affected, and the $\operatorname{IgA}$ concentration detected by ELISA was not obviously affected in the $\mathrm{C}$ and GOS A groups (Table 3). Thus, GOS administration may not affect S-IgA secretion in the small intestine.

In conclusion, dietary GOS suppressed eosinophil infiltration in the small intestine and tended to improve the growth performance of weaning piglets. Although further experiments are needed to elucidate the correlation between the eosinophil infiltration in the small intestine and growth performance, our data indicate the possibility that prevention of the eosinophil infiltration may improve the growth performance of weaning pigs.

ACKNOWLEDGMENTS. The authors thank Mr. M. Nishikawa and Ms. A. Kinoshita of the Kyoto Institute of Nutrition and Pathology for their technical assistance.

\section{REFERENCES}

1. Dreau, D., Lalles, J. P., Philouze-Rome, V., Toullec, R. and Salmon, H. 1994. Local and systemic immune responses to soybean protein ingestion in early-weaned pigs. J. Anim. Sci. 72: 2090-2098.

2. Godon, J. J., Zumstein, E., Dabert, P., Habouzit, F. and Moletta, R. 1997. Molecular microbial diversity of an anaerobic digestor as determined by small-subunit rDNA analysis. Appl. Environ. Microbiol. 63: 2802-2813.

3. Hirano, K., Shimojo, N., Katsuki, T., Ishikawa, N., Kohno, Y. and Niimi, H. 1997. Eosinophils in stool smear in normal and milk-allergic infants. Allergy 46: 594-601 (in Japanese).

4. Inoue, R., Tsukahara, T., Nakanishi, N. and Ushida, K. 2005. Development of the intestinal microbiota in the piglet. J. Gen. Appl. Mocrobiol. 51: 257-265.

5. Li, D. F., Nelssen, J. L., Reddy, P. G., Blecha, F., Klemm, R. and Goodband, R. D. 1991. Interrelationship between hypersensitivity to soybean proteins and growth performance in early-weaned pigs. J. Anim. Sci. 69: 4062-4069.

6. Makiyama, K., Kanzaki, S., Yamasaki, K., Zea-Iriarte, W. and Tsuji, Y. 1995. Activation of eosinophils in the pathophysiology of ulcerative colitis. J. Gastroenterol. 30: 64-69.

7. Mizubuchi, H., Yajima, T., Aoi, N., Tomita, T. and Yoshikai, Y. 2005. Isomalto-oligosaccharides polarize Th1-like 
responses in intestinal and systemic immunity in mice. $J$. Nutr. 135: $2857-2861$.

8. Ohshima, K-I. and Miura, S. 1961. Pathological study on an occurrence of swine edema disease in Iwate prefecture in 1959. Jpn. J. Vet. Sci. 23: 111-121.

9. Rothkotter, H. J., Kirchhoff, T. and Pabst, R. 1994. Lymphoid and non-lymphoid cells in the epithelium and lamina propria of intestinal mucosa of pigs. Gut 35: 1582-1589.

10. Roura, E., Homedes, J. and Klasing, K. C. 1992. Prevention of immunologic stress contributes to the growth-permitting ability of dietary antibiotics in chicks. J. Nutr. 122: 2383-2390.

11. Schley, P. D. and Field, C. J. 2002. The immune-enhancing effects of dietary fibres and prebiotics. Br. J. Nutr. 87: S221S230.

12. Sonoyama, K., Watanabe, H., Watanabe, J., Yamaguchi, N., Yamashita, A., Hashimoto, H., Kishino, E., Fujita, K., Okada, M., Mori, S., Kitahara, S. and Kawabata, J. 2005. Allergic airway eosinophilla is suppressed in ovalbumin-sensitized Brown Norway rats fed raffinose and alpha-linked galacto-oligosaccharide. J. Nutr. 135: 538-543.

13. Tsukahara, T., Iwasaki, Y., Nakayama, K. and Ushida, K. 2003. Stimulation of butyrate production in the large intestine of weaning piglets by dietary fructooligosaccharides and its influence on the histological variables of the large intestinal mucosa. J. Nutr. Sci. Vitaminol. 49: 414-421.

14. Tsukahara, T., Nakanishi, N., Nakayama, K., Matsubara, N. and Ushida, K. 2005. Experimental infection of enterotoxemic Escherichia coli associated with porcine edema disease and its pathologic characteristics in the intestine. J. Vet. Med. Sci. 67:
$1169-1173$

15. Tsukahara, T., Inoue, R., Nakanishi, N., Nakayama, K., Matsubara, N. and Ushida, K. 2007. Evaluation of the low dose level of a heat-killed and dried cell preparation of Enterococcus faecalis to prevent porcine edema disease using experimental infection model with enterotoxcemic Escherichia coli in weaning pigs. J. Vet. Med. Sci. 69: 103-109.

16. Ushida, K. and Sakata, T. 1998. Effect of pH on oligosaccharide fermentation by porcine cecal digesta. Anim. Sci. Technol. (Jpn.) 69: 100-107.

17. Ushida, K., Kameue, C., Tsukahara, T., Fukuta, K. and Nakanishi, N. 2008. Decreasing traits of fecal immunoglobulin A in neonatal and weaning piglets. J. Vet. Med. Sci. 70: 849-852.

18. Walker, C., Kaegi, M. K., Braun, P. and Blaser, K. 1991. Activated $\mathrm{T}$ cells and eosinophila in bronchoalveolar lavages from subjects with asthma correlated with disease severity. $J$. Allergy Clin. Immunol. 88: 935-942.

19. Yamashita, A., Hashimoto, H., Kitahara, S., Kikuchi, E., Fujita, K., Okada, M., Mizutani, A., Mori, S., Amano, Y. and Kanda, T. 2004. Production of $\alpha$-linked galactooligosaccharide ( $\alpha$-GOS) by $\alpha$-galactosidase from Aspergillus niger APC-9319 and its physical and physiological properties. J. Appl. Glycosci. 51: 115-122.

20. Yanai, H. 1998. Excel-toukei. Seiunsya, Tokyo (in Japanese).

21. Yoshikawa, T., Inoue, R., Yoshida, Y., Watanabe, T., Bukawa, W. and Ushida, K. 2009. Diverse immune responses to orally administered heat-killed cell preparation of Enterococcus faecalis strain EC-12 in murine immune tissues. Biosci. Biotechnol. Biochem. 73: 1439-1442. 